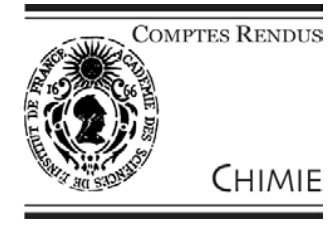

Metallodendritic catalysis

\title{
Recyclable nanosize homogeneous catalysts
}

\author{
Gerard P. M. van Klink, Harm P. Dijkstra, Gerard van Koten * \\ Department of Metal-Mediated Synthesis, Debye Institute, Utrecht University, Padualaan 8, 3584 CH, Utrecht, The Netherlands
}

Received 14 July 2003; accepted 28 July 2003

\begin{abstract}
For industrial chemical processes, it would be highly desirable from both a commercial and an environmental point of view to incorporate the advantages of homogeneous and heterogeneous catalysis into one chemical process. The ultimate goal is to design a catalytic system with the high activity and selectivity of homogeneous catalysts, the efficient catalyst recycling of heterogeneous catalysts and which has a high (thermal) stability for extended use. Ultimately, this leads to cleaner, faster and cheaper catalytic processes and eventually will lead to green commercial processes. To cite this article: G.P.M. van Klink et al., C. R. Chimie 6 (2003).
\end{abstract}

(C) 2003 Académie des sciences. Published by Éditions scientifiques et médicales Elsevier SAS. All rights reserved.

Keywords: homogeneous catalysis; organic supports; catalyst recycling

\section{Introduction}

Homogeneous catalysts are frequently used in highly selective organic transformations. Especially in asymmetric synthesis, the contribution of homogeneous catalysts is significant [1] because of a number of important advantages as compared to their heterogeneous counterparts. With the catalyst dissolved and all catalytic sites accessible, homogeneous catalysts are superior in terms of activity and selectivity and possess a high atom efficiency $[2,3]$. Furthermore, catalytic properties such as chemo-, regio-, and stereoselectivity can be tuned easily because of the well-defined nature of the homogeneous catalysts. Finally due to these beneficial features, homogeneous catalysts can in general be operated under mild reaction conditions.

\footnotetext{
* Corresponding author.

E-mail address: g.vankoten@chem.uu.nl (G. van Koten).
}

A major problem in the field of homogeneous catalysis though is separation of the catalyst from the product mixture. The commonly used method, separation by distillation, requires elevated temperatures that are not compatible with most homogeneous catalysts, which in general are thermally sensitive in nature. The homogeneous reactions that have been commercialised either involve volatile substrates and products or do not contain thermally sensitive organic ligands [3]. Both from a commercial and an environmental point of view it would be highly desirable to develop a general method that incorporates the advantages of homogeneous and heterogeneous catalysis into one chemical process. The ultimate goal is to design a catalytic system with a high activity and selectivity, an efficient catalyst recycling and which possesses a high stability. Ultimately, this leads to cleaner, faster and cheaper catalytic processes and eventually will lead to green commercial processes. 


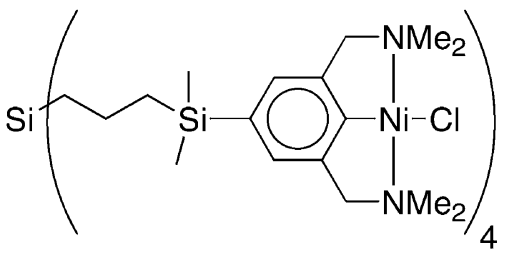

1

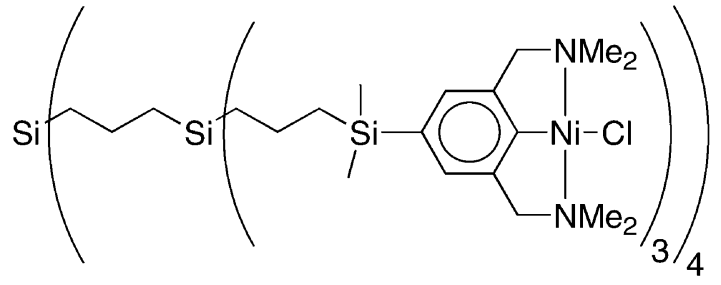

2

Fig. 1. Nickelated carbosilane dendrimers $\mathbf{1}$ and $\mathbf{2}$.

\section{Homogeneous catalysts on organic supports}

An attractive approach to design green commercial processes is the development of recyclable homogeneous catalysts [4]. One way of approaching this challenge is by anchoring the homogeneous catalyst on a large, soluble organic support that can be separated from the product mixture by nano- or ultrafiltration. The advantages of a soluble support are the equal distribution of the active catalytic sites throughout the reaction solution and preservation of the catalytic activity as compared to the corresponding non-supported homogeneous catalyst. Other commonly used approaches for catalyst recycling are the grafting of homogeneous catalysts to solid supports and the use of biphasic systems such as aqueous and fluorous biphasic catalysis, ionic liquids and supercritical fluids $[3,5,6]$.

\subsection{Homogeneous catalysts on dendritic supports}

Currently, there is considerable attention for the development of multimetallic, macromolecular assemblies for application in homogeneous catalysis under continuously operating conditions in a nanofiltration membrane reactor [2]. These nanosize homogeneous catalysts can be recovered in situ from the product stream by ultra- or nanofiltration techniques and reused again. Ultra- (UF) and nanofiltration (NF) membranes are defined to retain macromolecules with dimensions between 8 and $800 \mathrm{~nm}$ and 0.5 and $8 \mathrm{~nm}$, respectively. The recent development of solvent resistant nanofiltration membranes has made the nondestructive, energy efficient separation and concentration of reusable macromolecular catalysts from the product stream by filtration potentially feasible [7]. Already in 1994, the first example of such a macromo- lecular assembly, a so-called metallodendrimer (i.e. a dodecanickel carbosilane dendrimer), was used as a homogeneous catalyst in the regioselective Kharasch addition of polyhalogenoalkanes to $\mathrm{C}-\mathrm{C}$ double bonds [8]. This marked the beginning of the development of catalytically active metallodendrimers, a completely new research area in the field of dendrimer chemistry [9].

Recently, the soluble nickelated carbosilane dendrimers $\mathbf{1}$ and $\mathbf{2}$ (Fig. 1) were synthesized and their retention behaviour examined in a nanofiltration membrane reactor [10]. A filtration test (with 1) in a NFmembrane reactor (Fig. 2) showed retention of $97.4 \%$ of 1 in combination with the MPF-50 membrane. (SelRo-nanofiltration membranes (MPF-60, $\mathrm{MWCO}=400$ Da; MPF-50, MWCO = 700 Da) were purchased from Koch membrane Systems, Inc., Düsseldorf, Germany; further product information can be found at http://www.kochmembrane.com.) As promising as this seems, it means, however, that in a continu-

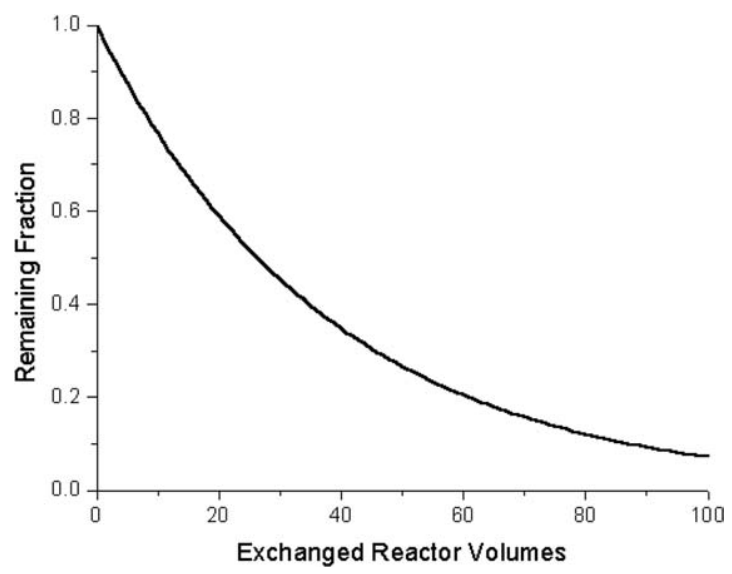

Fig. 2. Display of the retained fraction of $\mathbf{1}$ versus the number of exchanged reactor volumes in a nanofiltration membrane reactor. 
ous set-up after 30 exchanged reactor volumes already half the amount of catalytic material has been washed out. For 2, 99.8\% retention was found which still is not sufficient for operating under continuous reaction conditions (after 100 exchanged reactor volumes a washout of $20 \%$ is found). The size and molecular structures of complexes $\mathbf{1}$ and $\mathbf{2}$ were determined by molecular modelling studies. (For molecular modelling, the Spar$\tan$ 5.1.1 [SGI] program was used with MMFF94 as the force field.) Going from $\mathbf{1}$ to $\mathbf{2}$ the diameter significantly increases from 2 to $3 \mathrm{~nm}$. Remarkably, this $1 \mathrm{~nm}$ increase in radius resulted only in an increase of $2.4 \%$ in retention. These dendritic materials possess flexible backbones and are thus able to undergo shape-changes in solution [11]. This behaviour can affect their retention rates by nanofiltration membranes. Even highergeneration dendrimers are still not fully retained by NF-membranes. This behaviour most likely originates from the flexible backbone of these carbosilane dendritic catalysts; going up in generation does not necessarily results in a significant increase in the size of the dendrimers, but rather a back folding of the dendritic branches concomitant with denser molecules is encountered. In addition, the dendrimer size in solution is not well defined and varies upon altering the polarity of the solvent or when pressure is applied [12].

\subsection{Homogeneous catalysts on shape-persistent supports}

To study the role of flexibility of the carbosilane dendrimers on their retention behaviour, we started a detailed investigation on the influences of flexibility (rigidity), size, and geometry of macromolecular catalysts on their retention rate by nanofiltration membranes [13]. Investigating which of these parameters are important for the retention of macromolecules by NF-membranes would enable future predictions of the minimal size and optimal geometry needed for macro- molecular catalysts to obtain efficient retention rates. To investigate the importance of rigidity on the retention of macromolecules by NF-membranes shapepersistent catalysts containing rigid aromatic backbones were selected.

In order to prepare recyclable catalysts, the immobilization of so-called pincer catalysts on soluble or solid supports (Fig. 3) was intensively studied in recent years. It was demonstrated that the aryl-C4 position $\left(\mathrm{R}^{\prime \prime}\right)$ is an excellent branching point for anchoring these pincer complexes to support materials such as dendrimers, fullerenes, polymers, solid supports, and peptides $[8,10,14]$. The coordinating substituents E (mostly $\mathrm{NR}_{2}$, SR or $\mathrm{PR}_{2}$ ) can also be varied rather easily which has led to the incorporation of various (transition) metals into this monoanionic, terdentate coordinating ECE-ligand. Due to the stabilizing terdentate coordination mode of these metal complexes, they are also rather robust and do not suffer from deactivation or decomposition [15]. As a consequence these organometallic compounds can be used as catalyst in various organic reactions and are, therefore, suited for attachment to soluble organic macromolecular supports in order to create recyclable homogeneous catalysts.

For our studies to investigate the influences of flexibility (rigidity), size, and geometry of macromolecular complexes on their retention rate by nanofiltration membranes, the $\left[\mathrm{Pd}^{\mathrm{II}} \mathrm{X}(\mathrm{NCN})\right]$ moiety was used as the catalytically active site. This moiety was chosen because of its chemical and heat stability preventing deactivation and decomposition, as well as its high activity as a Lewis acid catalyst in Michael-type reactions [16]. Also, a series of mononuclear parasubstituted $\left[\mathrm{Pd}^{\mathrm{II}} \mathrm{X}(\mathrm{NCN})\right]$ complexes was synthesized to study the electronic influence of the para substituent, the anchoring point for immobilization, on the Lewis-acidic palladium centres by means of catalysis and DFT calculations [17]. This was done to estimate<smiles>[R7]c1cc(C([R7])F)c([Y10]([H])([H])F)c(C([R7])F)c1</smiles>

$$
\begin{aligned}
E & =\mathrm{NR}_{2}, \mathrm{PR}_{2}, \mathrm{SR} \\
\mathrm{M}= & \mathrm{Pd}, \mathrm{Pt}, \mathrm{Ni}, \mathrm{Ru}, \mathrm{Rh}, \mathrm{Ir}, \mathrm{Fe}, \mathrm{Au} \\
\mathrm{R}^{\prime}= & \text { hydrogen, alkyl } \\
\mathrm{R}^{\prime \prime}= & \text { hydrogen, alkyl, aryl, alkoxy, amide, } \\
& \text { dendrimer, fullerene, silica, peptides }
\end{aligned}
$$

Fig. 3. Metalated pincer complexes (for attachment) on supporting materials. 
beforehand any uncontrolled influences from these para functionalities on the catalytic activity of the pincer moiety when incorporated in a macromolecular complex. From these results, it became clear that in general the para substituents only slightly affect the catalytic activity of the palladium(II) centres. Thus, the pincer moiety possesses all desired properties to be incorporated into a recyclable macromolecular homogeneous catalyst and which also is stable under continuous operating conditions thereby retaining the catalytic activity of the non-supported pincer-metal complex.

Nanosize molecules with shape-persistent cores of types 3a-6a (Fig. 4, M = Pt, L = halide) were synthesized in order to investigate the influence of size and geometry on the retention rates of these macromolecules by MPF-60 and MPF-50 nanofiltration membranes [13]. As reference, the mononuclear [Pt$\mathrm{Br}(\mathrm{NCN})]$ complex $\mathbf{7 a}$ was also tested in a nanofiltration membrane reactor [18]. For the retention

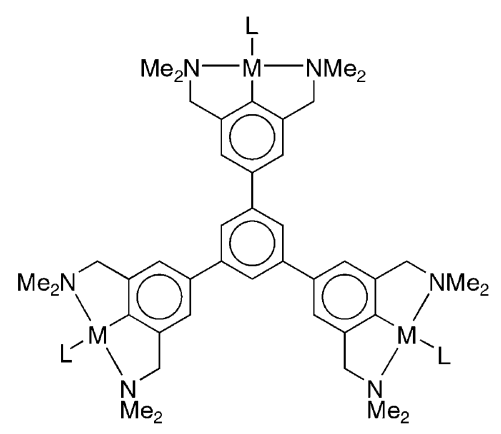

3

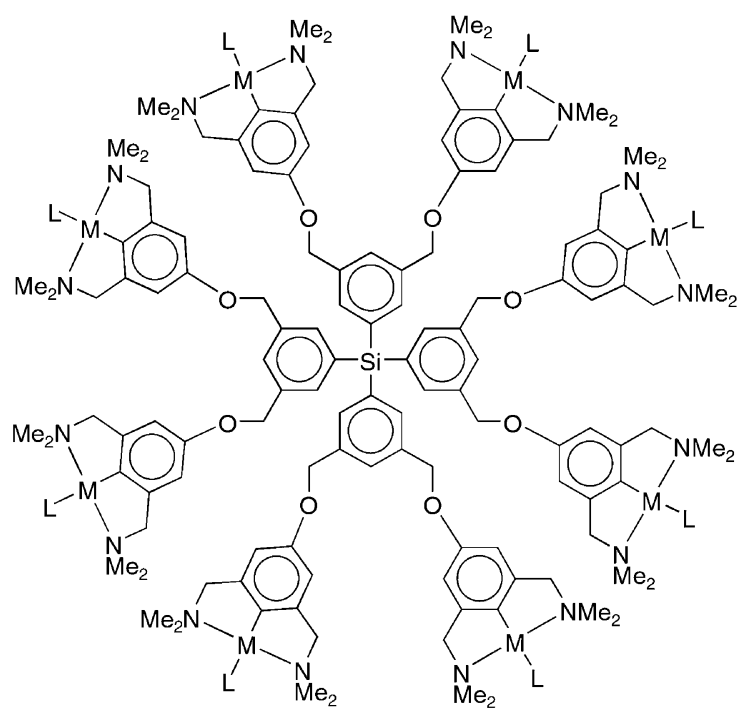

a: $\mathrm{M}=\mathrm{Pt}, \mathrm{L}=$ halide

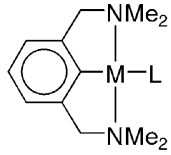

7 b: $M=P d, L=\mathrm{OH}_{2}\left(B_{4}\right)$
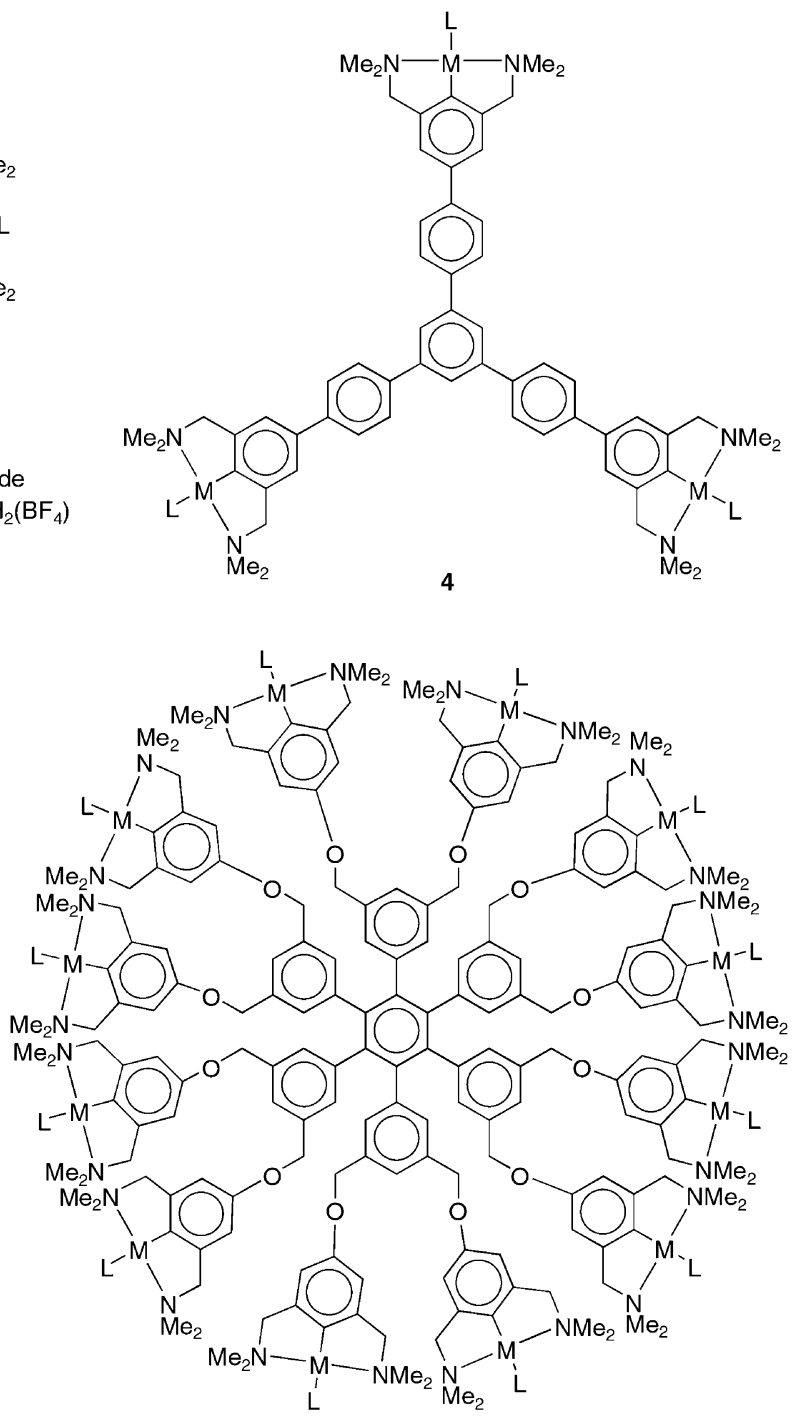

6

Fig. 4. Shape-persistent nanosize complexes. 
experiments the $[\mathrm{PtX}(\mathrm{NCN})]$ moiety (instead of the catalytically active Pd-analogue) was used because exposing these complexes in solution to gaseous $\mathrm{SO}_{2}$ results in an instantaneous colour change from colourless to deep orange due to the formation of a pentacoordinated platinum $\eta^{1}-\mathrm{SO}_{2}$ complex [14d, 19]. As a consequence, UV/Vis spectroscopy can be used to conveniently determine the concentration of the various complexes in both retentate and filtrate. To obtain impressions of the size and molecular structures of complexes 3a-7a, molecular modelling studies were performed on these platinum complexes. While in complexes 3a and 4a the organometallic sites are part of the shape-persistent core, $\mathbf{5} \mathbf{a}$ and $\mathbf{6 a}$ possess a more flexible organometallic shell around a rigid core [13]. Compounds 3a, 4a, and 7a are rather flat twodimensional structures while 5a possesses a spherically shaped, three-dimensional geometry. Despite the rigid two-dimensional core, 6a exerts a threedimensional structure due to the more flexible organometallic shell at its periphery.

The nanofiltration experiments were performed in a continuously operating high-pressure-membranereactor equipped with the MPF-60 or MPF-50 nanofiltration membrane. The concentrations of the multi(NCN-Pt) complexes in both the permeate and the retentate were determined and the resulting retention rates of the complexes are summarized in Table 1 [13]. With the MPF-60 membrane, the concentration of dodecakis(NCN-Pt) $6 \mathbf{a}$ in the permeate was below the detection limit of UV/Vis spectroscopy, i.e. a retention rate higher than $99.9 \%$. The three-dimensional octakis(NCN-Pt) 5a showed retention of $99.5 \%$. The two-dimensional phenylene-extended tris(pincer) $4 \mathbf{a}$ had a retention rate of $98.7 \%$, while for the tris(pincer) complex 3 retention dropped below the 94\%. The

Table 1

Retention rates of the various platinated NCN-pincer complexes

\begin{tabular}{lll}
\hline Compound & $R^{\mathrm{a}}(\%)(\mathrm{MPF}-60)$ & $R^{\mathrm{a}}(\%)(\mathrm{MPF}-50)$ \\
\hline $\mathbf{3}$ & 93.9 & n.d. \\
$\mathbf{4}$ & 98.7 & 97.6 \\
$\mathbf{5}$ & 99.5 & n.d. \\
$\mathbf{6}$ & $>99.9$ & 99.9 \\
$\mathbf{7}$ & 82.4 & n.d. \\
\hline
\end{tabular}

a The following formula was used for determining the retention rates: $R=1+\left(V_{\mathrm{t}} / V_{\mathrm{r}}\right) \ln \left(C_{\mathrm{f}} / C_{0}\right), V_{\mathrm{t}}=$ total volume flushed through membrane, $V_{\mathrm{r}}=$ reactor volume, $C_{\mathrm{f}}=$ concentration in filtrate, $C_{0}=$ initial concentration in the reactor. mononuclear NCN-pincer complex showed a retention rate of $82.4 \%$ only; the catalyst is completely washed out of the reactor within 30 cycles, which is far from being sufficient for continuous catalysis.

To further investigate the concept of shapepersistence in the core of the macromolecular catalysts for attaining optimal retentions, the retention rates of $4 \mathbf{a}$ and $6 \mathbf{a}$ were related to the calculated molecular volumes of these complexes. The same procedure was performed with the flexible $\mathrm{G} 0-\mathrm{Ni}_{4}, \mathbf{1}$, and $\mathrm{G} 1-\mathrm{Ni}_{12}, \mathbf{2}$, carbosilane dendrimers (Fig. 1) [10]. For 4a and 6a, molecular volumes of $1.2 \times 10^{3}$ and $4.4 \times 10^{3} \AA$, respectively, were derived by molecular modelling studies while the $\mathrm{G} 0-\mathrm{Ni}_{4}$ and the $\mathrm{G} 1-\mathrm{Ni}_{12}$ dendrimers 1 and 2 possess molecular volumes of $1.7 \times 10^{3}$ and $5.3 \times 10^{3} \AA^{3}$, respectively [13]. Earlier studies with the MPF-50 membrane yielded rates of retention of $97.4 \%$ for $\mathbf{1}$ and $\mathbf{9 9 . 8 \%}$ for $\mathbf{2}$, respectively. Thus, although $\mathbf{4 a}$ $(R=97.7 \%)$ and $6 \mathbf{a}(R=99.9 \%)$ possess smaller molecular volumes as compared to G0-1 and G1-dendrimer 2, respectively, the shape-persistent materials $4 \mathbf{a}$ and $\mathbf{6} \mathbf{a}$ are retained more efficiently by the nanofiltration membranes than the more flexible dendritic systems. Although these differences in retention seem rather small, under continuously operating reaction conditions, such small differences (between 0.1 and $0.5 \%$ ) already have a significant impact [2].

\subsection{Application in a nanofiltration membrane reactor under continuous reaction conditions}

For application as homogeneous catalysts in the double Michael reaction between methyl vinyl ketone (MVK) and ethyl $\alpha$-cyanoacetate complexes $\mathbf{3 b}-\mathbf{7 b}$ were synthesized (Fig. 4, $\mathrm{M}=\mathrm{Pd}, \mathrm{L}=\mathrm{OH}_{2}\left(\mathrm{BF}_{4}\right)$ ) [16, 17]. Compared to the catalytic activity of the reference monometallic catalyst $\mathbf{7 b}$, it became clear that the catalytic activities per $\mathrm{Pd}^{\mathrm{II}}$ centre for the multi(NCN$\mathrm{Pd}$ ) catalysts $\mathbf{3 b} \mathbf{- 5} \mathbf{b}$ were similar, indicating that all $\mathrm{Pd}^{\mathrm{II}}$ centres act as independent catalytic sites [17]. This implies an efficient use of all catalytic sites during catalysis and once again underlines that the Lewis acid catalytic activity is almost independent of the para functionality of the pincer moiety. Interestingly, dodecakis(NCN-Pd) 6b showed an almost threefold increase in catalytic activity per $\mathrm{Pd}^{\mathrm{II}}$ centre which is proposed to be due to cooperative effects between different catalytic sites, since the palladium centres are 
much closer together than in the other shape-persistent compounds [17,20].

Dodecakis(NCN-Pd) complex $\mathbf{6 b}$ was applied as a homogeneous catalyst in the double Michael reaction between MVK and ethyl $\alpha$-cyanoacetate under continuous reaction conditions in a nanofiltration membrane reactor [20]. Due to its macromolecular dimension, the catalyst is retained in the reactor during catalysis ( $R=99.5 \%$ determined by ICP-AAS). Complex $\mathbf{6 b}$ was found to be stable under the continuous reaction conditions as a constant activity was obtained at prolonged reaction times ( $26 \mathrm{~h}, 65$ exchanged reactor volumes). The total turnover number of the catalyst was thereby increased by a factor greater than 40 from 80 (batch) up to $>3000 \mathrm{~mol} \mathrm{molPd}^{-1}$ [20]. Thus, with a number of important conditions fulfilled, i.e. high rates of retention, high catalyst stability and solvent resistant membranes, membrane technology is very promising for extended application of homogeneous catalysts in industrial processes.

\section{Outlook}

An increasing number of macromolecular homogeneous catalysts is reported that show high retentions by NF-membranes [2]. In future, for NF-membrane technology to be applicable on a large industrial scale, research should be focused on the durability of the catalyst during catalysis. The endurance of many homogeneous catalysts, in contrast to heterogeneous catalysts, does not yet meet the requirements needed for long running continuous catalytic processes. For a broader application of homogeneous catalysts under continuous reaction conditions, both improvement of the membrane technology (especially more resistant membranes) and finding more catalytic systems that possess the required properties such as high retention rates and catalyst stability are of crucial importance. Furthermore, developing recyclable homogeneous catalysts based on a variety of different catalytic units is also desirable, since it allows the application of a broad range of selective organic transformations in a nanofiltration membrane reactor, the first step toward large-scale continuous processes.

\section{Conclusions}

Comparison between shape-persistent complexes and flexible carbosilane dendrimers of similar nanosize dimensions (according to molecular modelling), resulted in higher retentions for the shape-persistent complexes. Especially, by relating the molecular volumes of the various complexes to the retention rates, it became clear that shape-persistence is advantageous for obtaining optimal retentions by nanofiltration membranes. Therefore, for future development and application in the area of homogeneous catalyst recycling by nanofiltration membranes it is advisable to use macromolecular catalysts with a high degree of shapepersistence in the organic backbone.

\section{Acknowledgements}

We thank Mr. N. Ronde and Prof. Dr. D. Vogt (Technical University Eindhoven) for performing the nanofiltration experiments.

\section{References}

[1] R. Noyori, Asymmetric Catalysis in Organic Synthesis, Wiley, New York, 1994.

[2] H.P. Dijkstra, G.P.M. van Klink, G. van Koten, Acc. Chem. Res. 35 (2002) 798.

[3] D.J. Cole-Hamilton, Science 299 (2003) 1702.

[4] R.T. Baker, W. Tumas, Science 284 (1999) 1477.

[5] E. de Wolf, G. van Koten, B.J. Deelman, Chem. Soc. Rev. 28 (1999) 37.

[6] L.J.P. van den Broeke, E.L.V. Goetheer, A.W. Verkerk, E. de Wolf, B.J. Deelman, G. van Koten, J.T.F. Keurentjes, Angew. Chem. Int. Ed. Engl. 40 (2001) 4473.

[7] J.T. Scarpello, D. Nair, L.M. Freitas dos Santos, L.S. White, A.G. Livingstone, J. Membr. Sci. 203 (2002) 71.

[8] J.W.J. Knapen, A.W. van der made, J.C. de Wilde, P.W.N.M. van Leeuwen, P. Wijkens, D.M. Grove, G. van Koten, Nature 372 (1994) 659.

[9] For reviews on dendritic catalysts see: (a) R. Kreiter, A. Kleij, R.J.M. Klein Gebbink, G. van Koten, Top. Curr. Chem. 217 (2001) 163; (b) A.W. Kleij, A. Ford, J.T.B.H. Jastrzebski, G. van Koten, in: J. Fréchet, D. Tomalia (Eds.), Dendrimers and other Dendritic Polymers, Wiley, 2002, p. 185; (c) G.E. Oosterom, J.N.H. Reek, P. Kamer, P.W.N.M. van Leeuwen, Angew. Chem. Int. Ed. Engl. 40 (2001) 1828; (d) D. Astruc, F. Chardac, Chem. Rev. 101 (2001) 2991.

[10] A.W. Kleij, R.A. Gossage, R.J.M. Klein Gebbink, N. Brinkmann, E.J. Reijerse, U. Kragl, M. Lutz, A.L. Spek, G. van Koten, J. Am. Chem. Soc. 122 (2000) 12112. 
[11] (a) K. Wooley, C.A. Klug, K. Tasaki, J. Schaefer, J. Am. Chem. Soc. 119 (1997) 53; (b) M. Chai, Y. Niu, W.J. Youngs, P.L. Rinaldi, J. Am. Chem. Soc. 123 (2001) 4670.

[12] (a) S.S. Sheiko, M. Möller, Top. Curr. Chem. 212 (2001) 137; (b) M. Ballauff, Top. Curr. Chem. 212 (2001) 177.

[13] H.P. Dijkstra, C.A. Kruithof, N. Ronde, R. van de Coevering, D.J. Ramón, D. Vogt, G.P.M. van Klink, G. van Koten, J. Org. Chem. 68 (2003) 675.

[14] (a) D.E. Bergbreiter, P.L. Osburn, Y.-S. Liu, J. Am Chem. Soc. 121 (1999) 9531; (b) M. Albrecht, N.J. Hovestad, J. Boersma, G. van Koten, Chem. Eur. J. 7 (2001) 1289; (c) P.J. Davies, D.M. Grove, G. van Koten, Organometallics 16 (1997) 800; (d) M. Albrecht, R.A. Gossage, M. Lutz, A.L. Spek, G. van Koten, Chem. Eur. J. 6 (2000) 1431; (e) M.D. Meijer, N. Ronde, D. Vogt, G.P.M. van Klink, G. van Koten, Organometallics 20 (2000) 3993; (f) M. Albrecht, G. Rodríguez, J. Schoenmaker, G. van Koten, Org. Lett. 2 (2000) 3461; (g) G. Guillena, G. Rodríguez, M. Albrecht, G. van Koten, Chem. Eur. J. 8 (2002) 5368; (h) L.A. van der Kuil, D.M. Grove, J.W. Zwikker, L.W. Jenneskens, W. Drenth, G. van Koten, Chem. Mater. 6 (1994) 1675; (i) C. Patmamanohoran, P. Wijkens, D.M. Grove, A.P. Philipse, Langmuir 12 (1996) 4372.
[15] (a) G. van Koten, Pure Appl. Chem. 61 (1989) 1681; (b) M.H.P. Rietveld, D.M. Grove, G. van Koten, New. J. Chem. 21 (1997) 751; (c) B. Rybtchinski, D. Milstein, Angew. Chem. Int. Ed. 38 (1999) 870; (d) P. Steenwinkel, R.A. Gossage, G. van Koten, Chem. Eur. J. 4 (1998) 759.

[16] H.P. Dijkstra, M.D. Meijer, J. Patel, R. Kreiter, G.P.M. van Klink, M. Lutz, A.L. Spek, A.J. Canty, G. van Koten, Organometallics 20 (2001) 3159 .

[17] H.P. Dijkstra, M.Q. Slagt, A. McDonald, C.A. Kruithof, R. Kreiter, A.M. Mills, M. Lutz, A.L. Spek, W. Klopper, G.P.M. van Klink, G. van Koten, Eur. J. Inorg. Chem. (2003) 830.

[18] D.M. Grove, G. van Koten, J.N. Louwen, J.G. Noltes, A.L. Spek, H.J.C. Ubbels, J. Am. Chem. Soc. 104 (1982) 6609.

[19] M. Albrecht, R.A. Gossage, U. Frey, A.W. Ehlers, E.J. Baerends, A.E. Merbach, G. van Koten, Inorg. Chem. 40 (2001) 850.

[20] H.P. Dijkstra, N. Ronde, G.P.M. van Klink, D. Vogt, G. van Koten, Adv. Synth. Catal. 345 (2003) 364 